Article

\title{
Helicobacter Pylori Serology in Relation to Hepatitis C Virus Infection and IL28B Single Nucleotide Polymorphism
}

\author{
Alexander Gutwerk ${ }^{1}$, Thomas Wex ${ }^{1,2}$, Kerstin Stein $^{1}$, Cosima Langner ${ }^{1}$, Ali Canbay ${ }^{1}$, \\ Peter Malfertheiner ${ }^{1}$ and Alexander Link ${ }^{1, *}$ \\ 1 Department of Gastroenterology, Hepatology and Infectious Diseases, Otto-von-Guericke University \\ Magdeburg, Leipziger Str. 44, 39120 Magdeburg, Germany; alexander@gutwerk.de (A.G.); \\ t.wex@schenk-ansorge.de (T.W.); stein@hepatologie-magdeburg.de (K.S.); \\ Cosima.Langner@med.ovgu.de (C.L.); ali.canbay@med.ovgu.de (A.C.); \\ peter.malfertheiner@med.ovgu.de (P.M.) \\ 2 Medical Laboratories for Clinical Chemistry, Microbiology and Infectious Diseases, Department of \\ Molecular Genetics, 39124 Magdeburg, Germany \\ * Correspondence: alexander.link@med.ovgu.de or alinkmail@gmail.com; Tel.: +49-391-671-3745
}

Received: 27 December 2017; Accepted: 2 March 2018; Published: 5 March 2018

\begin{abstract}
The aim of the study was to evaluate the serological rate of Helicobacter pylori (H. pylori) infection in patients with chronic hepatitis $\mathrm{C}$ virus (HCV) infection and determine any correlations with liver damage and IL28B single-nucleotide polymorphism (SNP). One hundred eighty-nine patients with chronic HCV infection were included in the study, and H. pylori status was defined based on anti-H. pylori-IgG or anti-CagA-IgG antibodies using enzyme-linked immunosorbent assay (ELISA). Liver damage was assessed using histology or transient elastography. IL28B C/T polymorphism (rs12979860) was evaluated in circulating blood cells using a PCR-based restriction fragment length polymorphism assay. Overall $H$. pylori serology was positive in $38.1 \%$ of our $\mathrm{HCV}$-infected subjects. Among those, the anti-CagA-IgG positivity rate was $43.1 \%$ and was within the range of previously described populations of the same region. Highest prevalence of H. pylori was found in patients between 31 and 40 years compared to other age subgroups. The seropositivity rate was higher in the non-cirrhotic group than the cirrhotic one $(45.4 \%$ vs. $20.0 \%, p<0.05)$. No difference was found in IL28B genotype between H. pylori-positive and -negative cohorts. However, we observed a trend for the lower anti-CagA-IgG expression level in relation to the IL28B T-allele. Our results do not support an association between HCV and H. pylori infection. Whether IL28B SNP has a functional role in modulation of serological response to $H$. pylori CagA needs further investigation.
\end{abstract}

Keywords: Helicobacter pylori; hepatitis C virus; IL28B; rs12979860; CagA; serological rate; prevalence; cirrhosis; antibody

\section{Introduction}

Hepatitis C Virus (HCV) is a frequent infection, with up to 177 million people with present or past infections and an estimated global HCV prevalence around 2.5\% [1]. HCV infection has reached up to a $3.5 \%$ prevalence in the Middle East, in North Africa, and in Eastern and Central Asia [2]. The prevalence in Germany is reported between 0.3 and $0.6 \%$, which makes Germany a country with low prevalence within Europe [3,4]. Nevertheless, HCV infection is among the most important causes of chronic hepatitis, liver failure, and hepatocellular carcinoma (HCC) $[5,6]$. Furthermore, HCV has been considered a potential risk factor for intrahepatic cholangiocarcinoma and cancers of the pancreas, rectum, lung, and kidney $[7,8]$. 
H. pylori is an infectious disease that causes chronic gastritis and the majority of peptic ulcers $[9,10]$. More than $50 \%$ of the world's population is infected with H. pylori [11]. Prevalence is by far higher in developing countries, but even within Europe a higher prevalence in Eastern Europe, compared to Western Europe, has been found [7,11]. For the region of Saxony-Anhalt, Wex et al. evaluated H. pylori seropositivity in a large cohort of patients showing a seroprevalence of $44.4 \%$ [12]. Since H. pylori infection is usually acquired during childhood, multiple studies have proposed the so-called "birth-cohort effect", where the prevalence is higher in older groups and lower in young adults due to the decline in incidence of new infections $[7,12,13]$.

Several studies have suggested that the effect of $H$. pylori infection is not limited to the stomach. For example, De Martel et al. [14] reviewed several studies that evaluated an association between $H$. pylori infection and biliary tract cancers. Among those, two studies found no $H$. pylori in the biopsies of patients and the control group. The remaining six studies reported a higher proportion of $H$. pylori positivity in patients compared to the controls, suggesting a positive association between $H$. pylori infection and biliary tract cancer. Moreover, there seems to be a link between $H$. pylori infection and HCC. Xuan et al. calculated a summary odds ratio of 13.6 for the association of $H$. pylori infection with the risk for HCC [15]. A close relative of H. pylori, H. hepaticus led to the development of HCC in an experimental infection model in mice [16]. With this animal model system of a Helicobacter species inducing hepatitis on the one hand and HCV being responsible to a large extent for HCC on the other hand, there is ongoing debate regarding the interaction of $H$. pylori and chronic HCV infections and its influence on progression to liver cirrhosis and HCC. In a meta-analysis, Wang et al. evaluated 12 studies looking for H. pylori (serological or PCR) in HCV-infected patients with a total amount of 1449 patients (547 patients from China and 549 from Italy) and 2377 control cases [17]. Compared to the controls, they found an odds ratio (OR) of 2.93 having a positive test for $\mathrm{H}$. pylori in chronically infected HCV patients, no matter which state of HCV-related liver disease was present. In a subgroup analysis, the ORs were 4.48 for HCV-related cirrhosis and 5.45 for hepatocellular carcinoma [15]. The data, at least indirectly, implicate $\mathrm{H}$. pylori infection as a risk factor for the progression of chronic $\mathrm{HCV}$ infection to liver cirrhosis and HCC.

The rs12979860 C/T single nucleotide polymorphism (SNP) is located $3 \mathrm{~kb}$ upstream of the interleukin $28 B$ (IL28B) and is associated with spontaneous HCV clearance and HCV treatment success using historical pegINF and ribavirine-based therapy [18-21]. The presence of the $\mathrm{T} / \mathrm{T}$ genotype is associated with a higher Ishak-score, suggesting that $I L 28 B$ plays a role in the development of liver-fibrosis and -cirrhosis [19]. IL28B acts as an antiviral substance by regulating Treg cells and increasing adaptive cellular immunity stimulating genes through a Janus kinase (JAK) and Signal Transducer and Activator of Transcription (STAT) pathway [22,23]. Until now, no studies have evaluated the correlation between IL28B SNP and H. pylori infection.

Here, we evaluated the frequency of $H$. pylori infection in an $\mathrm{HCV}$ cohort with respect to liver cirrhosis in a tertiary medical center in Saxony-Anhalt in Germany. To estimate whether our results are within the range of other population cohorts in our region, we compared our data to recently published results. Furthermore, based on the known prognostic role of IL28B SNP in HCV treatment, H. pylori infection and seropositivity, for the first time, was correlated with IL28B polymorphism.

\section{Materials and Methods}

\subsection{Study Design}

From February 2011 to November 2015, we prospectively collected blood samples from HCV-infected patients treated in our outpatient unit of the Department of Gastroenterology, Hepatology and Infectious Diseases at Otto-von-Guericke University Magdeburg, Germany, for routine IL28B polymorphism analysis and evaluation of $H$. pylori status. All patients provided written informed consent for genetic analysis as part of the clinical routine testing. The study was evaluated 
by the local ethical committee and was given an exempt status for retrospective analysis of clinically obtained data.

\subsection{Determination of HCV Status}

Chronic HCV infection was evaluated by detecting anti-HCV antibodies either by the ECLIA test (anti-HCVII, Roche) or by quantitative RT-PCR using TaqMan 48 platform (Roche Diagnostics GmbH; Roche Applied Science, Mannheim, Germany). The detection limit (LOD) of this assay is $25 \mathrm{IU} / \mathrm{mL}$ serum. All analyses (including HBV and HIV diagnostics) were performed in the Central Clinical Laboratory of the Otto-von-Guericke University according to the manufacturer's recommendation.

\subsection{Determination of HCV IL28B SNP}

Several different types of IL28B SNP have been used to predict the sustained virologic response (SVR) or rapid virologic response (RVR) in HCV patients. rs12979860 SNP is among the most frequently used, and routine testing of HCV patients has been implemented in our department in the past. Furthermore, this SNP has been shown to correlate with SVR not only in Genotype 1 but also in Genotypes 2 and 3 [24,25]. HCV IL28B rs12979860 C/T polymorphism has been identified by a PCR-based restriction fragment length polymorphism assay, which provides results that are consistent with other methods $[19,26]$. Here, extraction of human genomic DNA from whole blood was performed using DNA Mini Kit (Qiagen, Hilden, Germany) following the manufacturer's recommendations. Amplification of DNA was done in a T3 Thermocycler machine (Biometra, Goettingen, Germany) with $15 \mu \mathrm{L}$ of HotStar Taq Plus DNA Polymerase Mix (Qiagen, Hilden, Germany), 9.6 $\mu \mathrm{L}$ of RNase-free water, $0.2 \mu \mathrm{L}$ each of forward (IL28B-F: 5'-gcttatcgcatacggctagg-3'; $50 \mu \mathrm{mol} / \mathrm{L}$ ) and reverse primer (IL28B-R: $5^{\prime}$-aggctcagggtcaatcacag- $3^{\prime} ; 50 \mu \mathrm{mol} / \mathrm{L}$ ), and $5 \mu \mathrm{L}$ of genomic DNA. The reactions were carried out as follows: enzyme activation at $95^{\circ} \mathrm{C}$ for $15 \mathrm{~min}, 45$ cycles of denaturation at $95^{\circ} \mathrm{C}$ for $30 \mathrm{~s}$, annealing at $60^{\circ} \mathrm{C}$ for $30 \mathrm{~s}$, extension at $72{ }^{\circ} \mathrm{C}$ for $1 \mathrm{~min}$, followed by final extension at $72{ }^{\circ} \mathrm{C}$ for $10 \mathrm{~min}$. After amplification of the $242 \mathrm{bp}$ fragment, an enzymatic digestion was performed with Bsh $1236 \mathrm{I}$ restriction endonuclease (Fermentas, Waltham, MA, USA). Ten microliters of PCR product were digested with $0.4 \mu \mathrm{L}$ of Bsh 1236I $(10 \mathrm{U} / \mu \mathrm{L})$ in $16.6 \mu \mathrm{L}$ of RNase-free water and $3 \mu \mathrm{L}$ of $10 \times$ Buffer $\mathrm{R}$ (Fermentas, Waltham, MA, USA) at $37^{\circ} \mathrm{C}$ overnight. Restriction products were analyzed by agarose gel electrophoresis, ethidium bromide staining, and Hyperladder IV (Bioline, Luckenwalde, Germany) as a molecular weight marker. An E.A.S.Y RH system (Herolab, Wiesloch, Germany) was used for gel imaging. The digested fragments were $135+82+25 \mathrm{bp}$ for the C-allele and $160+82 \mathrm{bp}$ for the T-allele.

\subsection{Determination of Liver Cirrhosis}

The presence of liver cirrhosis was assessed by either histopathological report or was indirectly

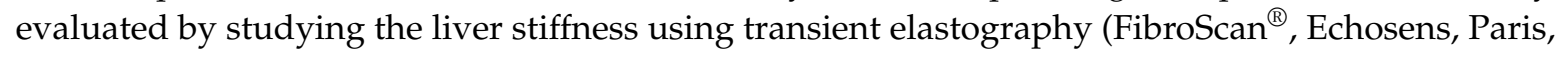
France) $[27,28]$.

\subsection{Determination of H. pylori Status}

Serological assessment of $H$. pylori status was performed as described previously [29]. Briefly, anti-H. pylori-IgG and anti-CagA antibodies were quantified using the H. pylori-IgG ELISA (Cat: 601040, BIOHIT, Helsinki, Finland) and the CagA-IgG kit (Cat: GD33, Genesis Diagnostics Ltd., London, UK) according to the manufacturer's instructions, severally. Based on the presence of $H$. pylori-specific $\operatorname{IgG}(>30 \mathrm{EIU} / \mathrm{mL})$ and/or the presence of anti-CagA $\operatorname{IgG}(>6.25 \mathrm{U} / \mathrm{mL})$, patients were classified as H. pylori-positive. Patients lacking both antibodies (anti-H. pylori IgG and anti-CagA IgG) were considered H. pylori-negative. 


\subsection{Comparison of the Data to the Previously Reported Cohorts}

To compare the results with previously available $H$. pylori seroprevalence from our region, we used two recently published cohorts. Wex et al. [12] have prospectively evaluated the $H$. pylori seropositivity in patients visiting our emergency department. Franck et al. [30] evaluated the H. pylori seropositivity in consecutive blood donors also in the same region. All studies used similar criteria for defining the H. pylori seropositivity and similar kits (described above) to avoid any methodological bias. For detailed information, we kindly refer to the original publications $[12,30]$.

\subsection{Statistical Analysis}

Data were entered into a database using Excel (Microsoft Office Package, Redmond, WA, USA). Age is shown as mean and standard deviations (mean \pm SD), and was analyzed by an unpaired Student's $t$-test. Categorical data (e.g., gender, H. pylori status) are presented as frequencies; comparisons were performed using the chi-square or Fisher's exact test. Differences in IL28B and H. pylori infection were compared by a Mann-Whitney test using two groups or a Kruskal-Wallis test for more than two groups. All tests were applied two-sided with a significance level of $p<0.05$.

\section{Results}

Patients' characteristics are presented in Table 1. Briefly, 105 out of 189 patients were males $(55.6 \%)$, and 84 were females $(44.4 \%)$. The mean age was 51.3 years ranging from 19 to 93 years. With respect to the origin of patients, Western and Eastern Europe were the main regions, $n=131 / 69.3 \%$ and $45 / 23.8 \%$, respectively. Few patients originated from Asia $(n=8)$ or other regions $(n=5)$. HCV genotype data were available for 182 patients with the majority of patients with Genotype $1 n=156$ (85.6\%). The remaining patients had Genotype $2 n=4(2.2 \%)$, Genotype $3 n=18(9.9 \%)$, Genotype 4 $n=3(1.6 \%)$, and Genotype $6 n=1(0.5 \%)$.

Table 1. Serological rate (\%) of H. pylori infection stratified by sex, ethnicity, other co-infections, and the presence of liver cirrhosis.

\begin{tabular}{|c|c|c|c|c|}
\hline \multirow{2}{*}{ Characteristic } & Total & H. pylori-Positive & H. pylori-Negative & \multirow{2}{*}{$p$-Value } \\
\hline & $n$ & $n(\%)$ & $n(\%)$ & \\
\hline HCV-positive & $189 *$ & $72(38.1 \%)$ & $117(61.9 \%)$ & n.s. \\
\hline $\begin{array}{l}\text { Gender } \\
\text { male } \\
\text { female }\end{array}$ & $\begin{array}{c}105 \\
84\end{array}$ & $\begin{array}{l}39(37.1 \%) \\
33(39.3 \%)\end{array}$ & $\begin{array}{l}66(62.9 \%) \\
51(60.7 \%)\end{array}$ & \\
\hline $\begin{array}{c}\text { Age } \\
\leq 40 \text { years } \\
>40 \text { years }\end{array}$ & $\begin{array}{c}51.32 \pm 13.4 \\
44 \\
145\end{array}$ & $\begin{array}{c}47.11 \pm 13.4 \\
27(61.4 \%) \\
45(31.0 \%)\end{array}$ & $\begin{array}{c}53.91 \pm 13.3 \\
17(38.6 \%) \\
100(69.0 \%)\end{array}$ & $\begin{array}{l}<0.001 \\
<0.001\end{array}$ \\
\hline $\begin{array}{c}\text { HCV genotype } \\
1 \\
2 \\
3 \\
4 \\
5 \\
6\end{array}$ & $\begin{array}{c}182 * \\
156 \\
4 \\
18 \\
3 \\
0 \\
1\end{array}$ & $\begin{array}{c}71(39.1 \%) \\
55(35.3 \%) \\
1(25 \%) \\
13(72.2 \%) \\
2(66.7 \%) \\
0 \\
0\end{array}$ & $\begin{array}{c}111(60.9 \%) \\
101(64.7 \%) \\
3(75 \%) \\
5(27.8 \%) \\
1(33.3 \%) \\
0 \\
1(100 \%)\end{array}$ & \\
\hline $\begin{array}{c}\text { Origin: } \\
\text { Western Europe } \\
\text { Eastern Europe }\end{array}$ & $\begin{array}{c}176^{*} \\
131 \\
45\end{array}$ & $\begin{array}{l}38(29.0 \%) \\
29(64.4 \%)\end{array}$ & $\begin{array}{l}93(71.0 \%) \\
16(35.6 \%)\end{array}$ & $<0.001$ \\
\hline $\begin{array}{c}\text { Coinfection to HCV: } \\
\text { None } \\
\text { HBV } \\
\text { HIV }\end{array}$ & $\begin{array}{c}188 * \\
158 \\
22 \\
8\end{array}$ & $\begin{array}{c}53(33.5 \%) \\
15(68.2 \%) \\
3(37.5 \%)\end{array}$ & $\begin{array}{c}105(66.5 \%) \\
7(31.8 \%) \\
5(62.5 \%)\end{array}$ & $<0.005$ \\
\hline
\end{tabular}


Table 1. Cont

\begin{tabular}{ccccc}
\hline \multirow{2}{*}{ Characteristic } & Total & H. pylori-Positive & H. pylori-Negative & \multirow{2}{*}{$\boldsymbol{p}$-Value } \\
\cline { 2 - 3 } & $\boldsymbol{n}$ & $\boldsymbol{n} \mathbf{( \% )}$ & $\boldsymbol{n} \mathbf{( \% )}$ & \\
\hline Liver status: & $189^{*}$ & & & \\
no liver cirrhosis & 134 & $61(45.5 \%)$ & $73(54.5 \%)$ & $<0.005$ \\
liver cirrhosis & 55 & $11(20.0 \%)$ & $44(80.0 \%)$ & \\
\hline IL28B-SNP genotype & $169^{*}$ & & & \\
C/C & 45 & $19(42.2 \%)$ & $26(57.8 \%)$ & n.s. \\
C/T & 91 & $32(35.2 \%)$ & $59(64.8 \%)$ & \\
T/T & 33 & $13(39.4 \%)$ & $20(60.6 \%)$ & \\
\hline
\end{tabular}

Data shown as the absolute number with $\%$ or as the mean \pm SD. ${ }^{*}$ retrospectively not all data were available systematically for all subjects. Analyses were done with chi-square or Fisher's exact tests with the exception of \# where an unpaired $t$-test was used; n.s. = not significant. HBV infection is defined by positive HBs-Ag and/or HBV-DNA to exclude past HBV infection.

The overall serological rate of $H$. pylori antibodies in our cohort was $38.1 \%$, without any difference between males and females (Table 1). Ethnicity was associated with a higher H. pylori detection rate for Eastern Europe compared to Western countries (64.4\% vs. $29 \%, p<0.001)$. Patients co-infected with HBV demonstrated a significantly higher rate of $H$. pylori seropositivity compared to those without coinfection. Furthermore, patients with Genotypes 3 and 4 compared with those with Genotype 1, showed higher $H$. pylori seropositivity. Interestingly, patients with cirrhosis had a significantly lower H. pylori seropositivity rate than those without cirrhosis (Table 1); this was in spite of the older age of cirrhotic groups, compared to non-cirrhotic groups (60.6 vs. 47.5 years).

H. pylori seropositivity showed no birth-cohort effect compared to similar population-based studies (Figure 1). The positive H. pylori status was found to be significantly higher for patients from 31 to 40 years, whereas younger and older subgroups revealed similar rates between $31 \%$ and $39 \%$. Compared to two other studies from the same local area of Saxony-Anhalt, the serological $H$. pylori positivity rate in the $\mathrm{HCV}$ cohort was lower than that in the general population, but higher than those identified in healthy blood donors [12,30]. In comparison to previously published results, we were unable to observe a typical age-related "birth-cohort effect", suggesting that, in the HCV cohort, additional factors likely included a typical distribution with an increasing $H$. pylori positivity in older patients (Table 2).

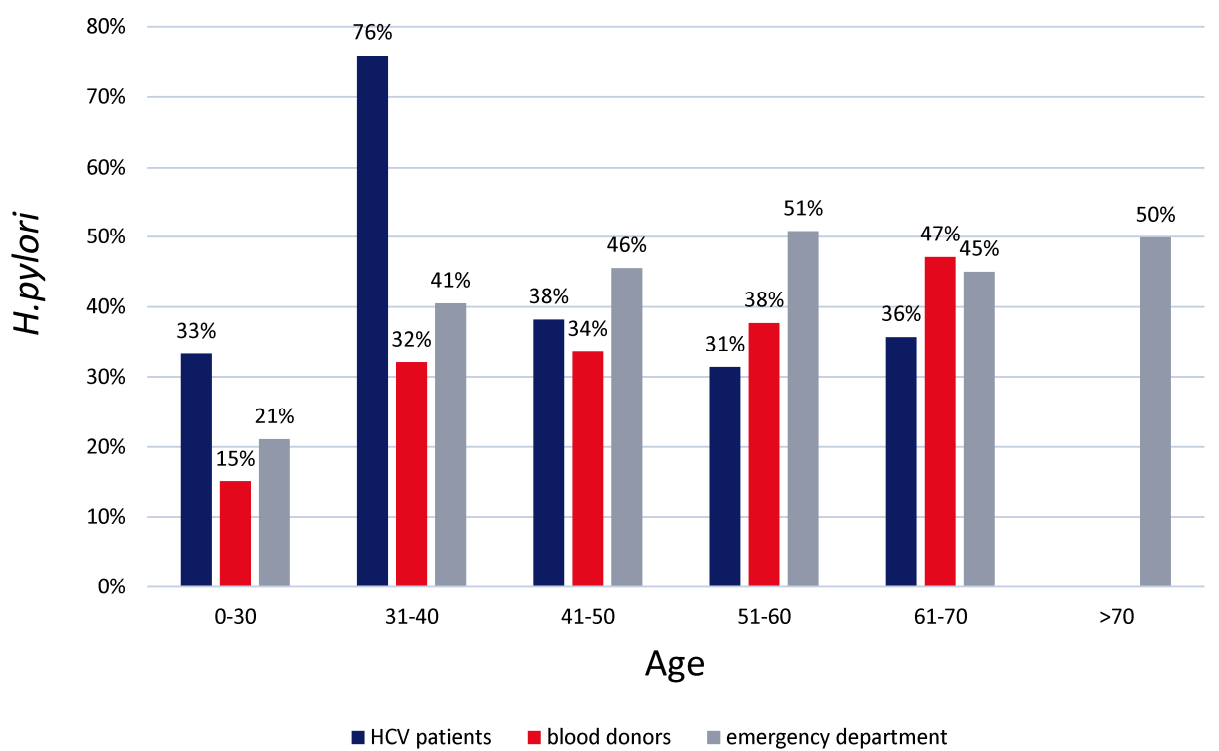

Figure 1. Distribution of H. pylori infection in our cohort in comparison to the general population (subjects in emergency department [12] and healthy blood donors [30]) estimated using two independent cohorts. 
Table 2. Serological rate of H. pylori infection in the HCV cohort stratified by age.

\begin{tabular}{cccc}
\hline \multirow{2}{*}{ Age in Years } & \multicolumn{3}{c}{ No. of H. pylori-Positive Subjects/All Subjects (\%) } \\
\cline { 2 - 4 } & Current Study & Wex et al. 2011 & Franck et al. 2017 \\
\hline overall & $72 / 189(38.1 \%)$ & $1029 / 2318(44.4 \%)$ & $149 / 516(28.9 \%)$ \\
$\leq 30$ & $5 / 15(33.3 \%)$ & $61 / 289(21.1 \%)$ & $15 \%$ \\
$31-40$ & $22 / 29(75.9 \%)$ & $75 / 185(40.5 \%)$ & $32 \%$ \\
$41-50$ & $13 / 34(38.2 \%)$ & $122 / 268(45.5 \%)$ & $34 \%$ \\
$51-60$ & $22 / 70(31.4 \%)$ & $167 / 329(50.8 \%)$ & $38 \%$ \\
$61-70$ & $10 / 28(35.7 \%)$ & $167 / 371(45.0 \%)$ & $47 \%$ \\
$>70$ & $0 / 13(0 \%)$ & $437 / 876(49.9 \%)$ & n.a. ${ }^{*}$ \\
\hline
\end{tabular}

Relative proportion of H. pylori seropositivity in subjects presented in emergency department (Wex et al. 2011) [12] or in blood donors (Franck et al. 2017) [31]. H. pylori positivity status was defined in all three studies using similar criteria: anti-H. pylori-IgG+ and/or anti-CagA-IgG+. n.a.* age of $>70$ years was an exclusion criteria for blood donation and therefore not available.

\section{H. pylori Infection and IL28B Genotype}

The role of IL28B in H. pylori infection had not been previously studied. We questioned whether patients with different IL28B genotypes have different immune responses during $H$. pylori infection. Here, we evaluated the serological anti-H. pylori-IgG and anti-CagA-IgG from H. pylori-infected subjects in relation to different IL28B genotypes. As shown in Table 1 and Figure 2, there was no significant difference in $H$. pylori seropositivity in the different IL28B genotypes, suggesting a similar distribution of IL28B polymorphisms among $H$. pylori-positive and -negative cohorts. In a recent study, we showed that CagA-seropositivity may be dependent on various factors and hypothesized the role of genetics [29]. Therefore, we evaluated whether IL28B SNP has any association with H. pylori/CagA-seropositivity. No difference was found in anti-H. pylori-IgG levels. However, there was a remarkable trend for lower anti-CagA-IgG levels in patients with the IL28B SNP genotype, which was true for both $\mathrm{T} / \mathrm{T}(p=0.113)$ and T-allele $(p=0.077)$ in comparison to patients with $\mathrm{C} / \mathrm{C}$ and $\mathrm{C} / \mathrm{T}$ genotypes or C-allele, respectively (Figure 2). Since our cohort of HCV-infected subjects included HBV and HIV-coinfected patients, we questioned whether co-infection with HIV in particular could lead to lower antibody levels. The analysis of IL28B SNP revealed, however, that all HIV co-infected subjects had either a $\mathrm{C} / \mathrm{C}$ or a $\mathrm{C} / \mathrm{T}$ genotype and therefore showed no association with lower anti-CagA-IgG. Furthermore, the proportion of HBV-co-infected subjects, based on the IL28B SNP, was similar to that of the total HCV cohort, with C/C 30\%, C/T 60\%, and T/T 10\% compared to the total HCV cohort with C/C $28 \%$, C/T 54\%, and T/T 19\%. Therefore, at least based on our data we did not observe any correlation between HBV and HIV co-infection and lower anti-CagA-IgG with relation to IL28B SNP.

A

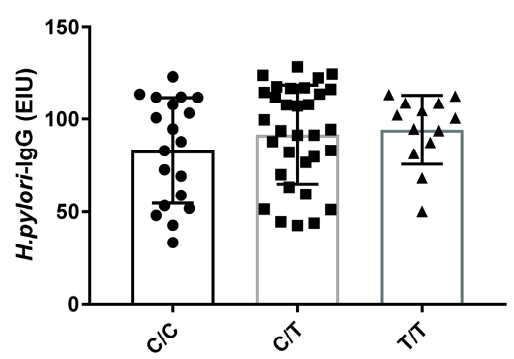

B

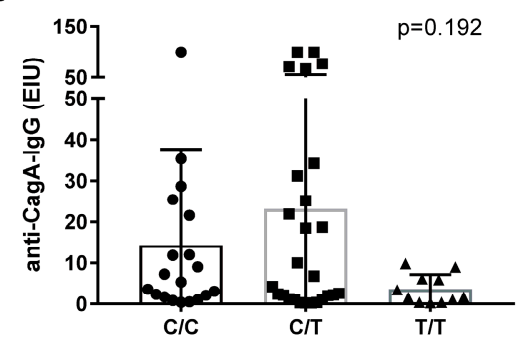

Figure 2. Cont. 


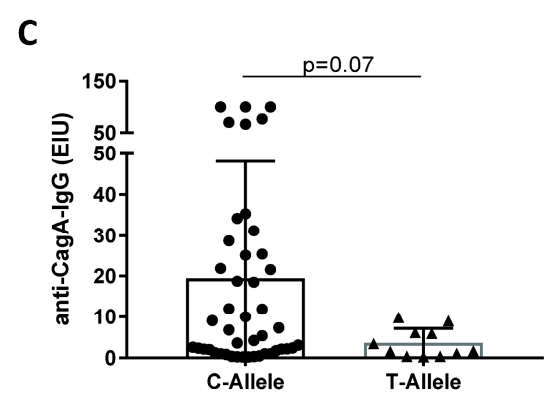

Figure 2. H. pylori and anti-CagA-seropositivity in relation to IL28B SNP. (A) Anti-H. pylori-IgG in IL28B C/C, C/T and T/T genotypes. (B) Anti-CagA-IgG in IL28B C/C, C/T, and T/T genotypes. (C) Anti-CagA-IgG in IL28B C- and T-alleles. Two groups were compared using a Mann-Whitney test and more than two groups using a Kruskal-Wallis multiple comparison test.

\section{Discussion}

This work provides an up-to-date view on the prevalence of H. pylori infection in HCV-infected subjects and provides initial data for a potential correlation between IL28B polymorphisms and CagA-seropositivity. We show that patients in the HCV cohort have similar H. pylori positivity as the general population in the same region; however, the presence of liver cirrhosis was associated with a lower $H$. pylori positivity rate.

Overall H. pylori positivity rate of about $38 \%$ in the HCV cohort fits with epidemiological data from other European countries [32], in particular with the studies from Germany [33,34] and with the region of Saxony-Anhalt $[12,30]$. The high serological H. pylori rate in younger patients, in particular those between 30 and 40 years, corresponds to other studies showing an elevation of $H$. pylori seroprevalence in HCV patients, for example [17]. However, in contrast, our data does not provide any evidence for potential interaction between either infection since $H$. pylori and $\mathrm{HCV}$ infections are acquired at different ages. In our study cohort, approximately $50 \%$ of all patients positive for $H$. pylori in the group of 31-40 years were immigrants from Eastern Europe. Therefore, the rather high $H$ pylori rate in this group (31-40 years) may be driven by the inclusion of $\mathrm{HCV}$ patients from areas with high $H$. pylori prevalence, with potential differences in transmission [35-39].

Interestingly, in contrast to previous studies from our region [12,30], we observed a missing "birth-cohort effect" in HCV-infected subjects; this observation implies additional factors or potential selection bias. The subjects from our cohort were recruited from a tertiary center where the majority of patients underwent specialized medical care. This includes regular visits, especially in the era of interferon-based therapy. In particular, those patients with liver fibrosis/cirrhosis were very likely to undergo additional diagnostics, including upper GI-endoscopy on a routine basis for a screening of varices during long-term follow-up. The routine workup in Europe is to perform histology, which substantially increases the chance of $H$. pylori detection, and eradication was accordingly offered to everyone even though the majority of patients were probably asymptomatic [40,41]. However, even regular contact with a gastroenterologist/hepatologist makes it more likely that $H$. pylori infection is detected by chance or with mild symptoms. Perez-Perez et al. discussed this aspect in a study where a lower serological $H$. pylori rate was also identified frequently in patients with regular contact to medical practitioners [42]. Our data support this conclusion although the clinically relevant meaning of the data has yet to be obtained. Notably, the majority of guidelines with a scope to cirrhosis and portal hypertension recommend screening for esophageal varices by EGD [43]. Therefore, this strategy may increase the likelihood of detecting $H$. pylori infection with subsequent eradication therapy leading to lower H. pylori infection rates in patients with cirrhosis. In addition, as patients suffering from liver cirrhosis were older than patients without cirrhosis, we assume that the intensive medical care due to advanced liver damage (cirrhosis) might lead to lower H. pylori rates in elderly patients, whereas the inclusion of patients from countries with a high prevalence of $H$. pylori led to higher $H$. pylori rates in 
younger patients. Together, this might explain the unusual age-related pattern of $H$. pylori seropositivity. We speculate that testing for $\mathrm{H}$. pylori infection in addition to $\mathrm{HCV}$ testing would provide an additional long-term health benefit for patients, reducing the chance of developing preneoplastic conditions or complications such as peptic ulcer or gastric cancer.

IL28B SNP is well known to influence spontaneous and treatment-induced clearance of HCV infection $[19,20]$. In this work, a possible association between IL28B SNP and H. pylori was evaluated for the first time. First, we found no difference in IL28B genotypes among the H. pylori-positive and $H$. pylori-negative groups, which indirectly confirms the validity of the groups. Second, in our previous work, we found that only around $32.3 \%$ of subjects that have H. pylori infection and H. pylori CagA positive strains have a positive serology [29]. Although we found crucial evidence for the role of the $v a c A$ genotype as an important determinant for seropositivity, we also questioned whether the presence of potential genetic host factors could have an influence on the serological profile. Because of the pronounced role of IL28B in the immune response to $\mathrm{HCV}$ infection, we further questioned whether IL28B could be involved in $H$. pylori infection. The association analysis of the IL28B SNP genotype revealed a trend for the lower anti-CagA-IgG in subjects with $\mathrm{T} / \mathrm{T}$-genotype and T-allele; in other words, none of the subjects with a T/T genotype had high anti-CagA-IgG levels. As discussed, there may be multiple factors such as genetic polymorphism — such as HLA or, in our case, IL28B — which are likely to be associated with immune response on $H$. pylori and therefore serological conversion [44]. Furthermore, it is reported that the IL28B C/C genotype is generally more frequent in subjects in East Asia [19] and that Asian countries have a rather high anti-CagA-seropositivity frequency compared to other countries [29]. At this stage, we may only speculate that C- or T-alleles of IL28B SNP could be involved in the modulation of immunological response to the CagA virulence factor. However, it needs to be mentioned that the number of $H$. pylori positive patients with IL28B T/T genotype was quite small and that further studies are needed.

There are several limitations that need to be mentioned. First of all, the number of samples is relatively small, which is at least partly related to the low $\mathrm{HCV}$ infection prevalence from one side and to changes in therapeutic management with the availability of new effective drugs that make IL28B testing unnecessary. Because of the limited sample size, we did not perform any additional subgroup analysis to evaluate an association between $\mathrm{HCV}$ and H. pylori. As we show the lower H. pylori seropositivity in cirrhotic patients, we believe that this could be related to prior eradication treatments. Unfortunately, because of the retrospective data analysis, we could not obtain data regarding former eradications/visits. The main novelty of the work, however, is related to the IL28B SNP and H. pylori analysis. Nevertheless, we only implemented rs12979860 SNP, which shows a good correlation to sustained viral response. Other types of SNP of the IL28B gene may be important as well and need to be considered in the future $[24,25]$. Finally, we provide the data to IL28B SNP in HCV-infected subjects. Whether a similar immunological pattern or correlation can be found in HCV-negative cohorts, especially taking into account the origin of the patients (European vs. Asian), needs to be addressed in the future. With the availability of highly effective anti-HCV drugs, however, the question regarding the hypothetical interaction/association between $H$. pylori and HCV may be more difficult to address.

\section{Conclusions}

We demonstrate that the serological rate of $H$. pylori in patients with chronic HCV was within the range of seropositivity previously described for the same region. The highest $H$. pylori rate was found in young adults, while the lowest rate was found in patients with liver cirrhosis. Analysis of the IL28B rs12979860 polymorphism revealed a trend for the lower anti-CagA-IgG seropositivity related to T-alleles. Whether IL28B SNP may be associated with host-dependent modulation of serological response to $H$. pylori infection needs to be confirmed in the future. Furthermore, further evaluation is required to determine whether $H$. pylori infection may be associated with worse outcome or prognosis 
in HCV patients and whether $H$. pylori eradication may provide an objectively measurable long-term benefit to $\mathrm{HCV}$ infected subjects in addition to healthy gastric mucosa.

Acknowledgments: We would like to our team at the GI research laboratory, specifically Ursula Stolz and Marion Holley, for their assistance.

Author Contributions: Kerstin Stein and Peter Malfertheiner designed the study; Alexander Gutwerk, Kerstin Stein, Cosima Langner, and Alexander Link performed the analysis; Alexander Gutwerk, Kerstin Stein, Thomas Wex, and Alexander Link analyzed the data; Peter Malfertheiner, Ali Canbay, and Alexander Link critical evaluation of the topic; Alexander Gutwerk, Thomas Wex, and Alexander Link wrote the paper; all authors contributed significantly to the manuscript and agreed to the final version of the manuscript.

Conflicts of Interest: The authors declare no conflict of interest.

\section{References}

1. Petruzziello, A.; Marigliano, S.; Loquercio, G.; Cozzolino, A.; Cacciapuoti, C. Global epidemiology of hepatitis $C$ virus infection: An up-date of the distribution and circulation of hepatitis $C$ virus genotypes. World J. Gastroenterol. 2016, 22, 7824-7840. [CrossRef] [PubMed]

2. Webster, D.P.; Klenerman, P.; Dusheiko, G.M. Hepatitis C. Lancet 2015, 385, 1124-1135. [CrossRef]

3. Poethko-Müller, C.; Zimmermann, R.; Hamouda, O.; Faber, M.; Stark, K.; Ross, R.S.; Thamm, M. Die Seroepidemiologie der Hepatitis A, B und C in Deutschland. Bundesgesundheitsblatt Gesundheitsforschung Gesundheitsschutz 2013, 56, 707-715. [CrossRef] [PubMed]

4. Vermehren, J.; Schlosser, B.; Domke, D.; Elanjimattom, S.; Müller, C.; Hintereder, G.; Hensel-Wiegel, K.; Tauber, R.; Berger, A. High prevalence of anti-HCV antibodies in two metropolitan emergency departments in Germany: A prospective screening analysis of 28,809 patients. PLoS ONE 2012, 7, e41206. [CrossRef] [PubMed]

5. Au, T.H.; Destache, C.J.; Vivekanandan, R. Hepatitis C therapy: Looking toward interferon-sparing regimens. J. Am. Pharm. Assoc. 2015, 55, e72-e86. [CrossRef] [PubMed]

6. Sarrazin, C.; Berg, T.; Ross, R.; Schirmacher, P.; Wedemeyer, H.; Neumann, U.; Schmidt, H.H.; Spengler, U.; Wirth, S.; Kessler, H.H.; et al. Update der S 3-Leitlinie Prophylaxe, Diagnostik und Therapie der Hepatitis-C-Virus(HCV)-Infektion, AWMF-Register-Nr.: 021/012. Prophylaxis, diagnosis and therapy of Hepatitis $\mathrm{C}$ virus (HCV) infection: The German guidelines on the management of HCV infection. Z. Gastroenterol. 2010, 48, 289-351. [CrossRef] [PubMed]

7. Allison, R.D.; Tong, X.; Moorman, A.C.; Ly, K.N.; Rupp, L.; Xu, F.; Gordon, S.C.; Holmberg, S.D. Increased incidence of cancer and cancer-related mortality among persons with chronic hepatitis C infection, 2006-2010. J. Hepatol. 2015, 63, 822-828. [CrossRef] [PubMed]

8. Shaib, Y.H.; El-Serag, H.B.; Nooka, A.K.; Thomas, M.; Brown, T.D.; Patt, Y.Z.; Hassan, M.M. Risk factors for intrahepatic and extrahepatic cholangiocarcinoma: A hospital-based case? control study. Am. J. Gastroenterol. 2007, 102, 1016-1021. [CrossRef] [PubMed]

9. Sugano, K.; Tack, J.; Kuipers, E.E.J.; Graham, D.Y.; El-Omar, E.M.; Miura, S.; Haruma, K.; Asaka, M.; Uemura, N.; Malfertheiner, P. Kyoto global consensus report on Helicobacter pylori gastritis. Gut 2015, 64, 1353-1367. [CrossRef] [PubMed]

10. Malfertheiner, P.; Link, A.; Selgrad, M. Helicobacter pylori: Perspectives and time trends. Nat. Rev. Gastroenterol. Hepatol. 2014, 11, 628-638. [CrossRef] [PubMed]

11. Dunn, B.E.; Cohen, H.; Blaser, M.J. Helicobacter pylori. Clin. Microbiol. Rev. 1997, 10, 720-741. [PubMed]

12. Wex, T.; Venerito, M.; Kreutzer, J.; Götze, T.; Kandulski, A.; Malfertheiner, P. Serological prevalence of Helicobacter pylori infection in Saxony-Anhalt, Germany, in 2010. Clin. Vaccine Immunol. 2011, 18, $2109-2112$. [CrossRef] [PubMed]

13. Kuipers, E.J. Helicobacter pylori and the risk and management of associated diseases: Gastritis, ulcer disease, atrophic gastritis and gastric cancer. Aliment. Pharmacol. Ther. 1997, 11, 71-88. [CrossRef] [PubMed]

14. De Martel, C.; Plummer, M.; Parsonnet, J.; Van Doorn, L.J.; Franceschi, S. Helicobacter species in cancers of the gallbladder and extrahepatic biliary tract. Br. J. Cancer 2009, 100, 194-199. [CrossRef] [PubMed]

15. Xuan, S.Y.; Xin, Y.N.; Chen, A.J.; Dong, Q.J.; Qiang, X.; Li, N.; Zheng, M.H.; Guan, H.S. Association between the presence of $\mathrm{H}$ pylori in the liver and hepatocellular carcinoma: A meta-analysis. World J. Gastroenterol. 2008, 14, 307-312. [CrossRef] [PubMed] 
16. Ward, J.M.; Anver, M.R.; Haines, D.C.; Benveniste, R.E. Chronic active hepatitis in mice caused by Helicobacter hepaticus. Am. J. Pathol. 1994, 145, 959-968. [PubMed]

17. Wang, J.; Li, W.-T.; Zheng, Y.-X.; Zhao, S.-S.; Li, N.; Huang, Y. The Association between Helicobacter pylori infection and chronic hepatitis C: A meta-analysis and trial sequential analysis. Gastroenterol. Res. Pract. 2016, 2016, 8780695. [CrossRef] [PubMed]

18. Ghany, M.G.; Nelson, D.R.; Strader, D.B.; Thomas, D.L.; Seeff, L.B. An update on treatment of Genotype 1 chronic hepatitis $C$ virus infection: 2011 practice guideline by the American Association for the Study of Liver Diseases. Hepatology 2011, 54, 1433-1444. [CrossRef] [PubMed]

19. Taheri, S.; Aygen, B.; Korkmaz, K.; Yıldız, O.; Zararsız, G.; Canatan, H. Characterization of the interleukin-28B gene rs12979860 C/T polymorphism in Turkish chronic hepatitis $\mathrm{C}$ patients and healthy individuals. Balkan Med. J. 2015, 32, 147-155. [CrossRef] [PubMed]

20. Thomas, D.L.; Thio, C.L.; Martin, M.P.; Qi, Y.; Ge, D.; O’hUigin, C.; Kidd, J.; Kidd, K.; Khakoo, S.I.; Alexander, G.; et al. Genetic variation in IL28B and spontaneous clearance of hepatitis C virus. Nature 2009, 461, 798-801. [CrossRef] [PubMed]

21. Falleti, E.; Bitetto, D.; Fabris, C.; Cussigh, A.; Fornasiere, E.; Cmet, S.; Fumolo, E.; Bignulin, S.; Fontanini, E.; Cerutti, A.; et al. Role of interleukin 28B rs12979860 C/T polymorphism on the histological outcome of chronic hepatitis C: Relationship with gender and viral genotype. J. Clin. Immunol. 2011, 31, 891-899. [CrossRef] [PubMed]

22. Bruno, S.; Thompson, A.J.; Critelli, R.; Crosignani, A.; Rossi, S.; De Lisi, S.; Cariani, E.; Zermiani, P.; Vaira, V.; Boccaccio, V.; et al. Interferon lambda-3 is not associated with clinical outcome in patients with HCV-induced compensated cirrhosis: A long-term cohort study. Antivir. Res. 2015, 113, 27-32. [CrossRef] [PubMed]

23. Tameshkel, F.S.; Niya, M.H.; Sohrabi, M.; Panahi, M.; Zamani, F.; Imanzade, F.; Rakhshani, N. Polymophism of IL-28B gene (rs12979860) in HCV genotype 1 patients treated by pegylated interferon and ribavirin. Iran. J. Pathol. 2016, 11, 216-221.

24. Aziz, H.; Raza, A.; Ali, K.; Khattak, J.Z.K.; Irfan, J.; Gill, M.L. Polymorphism of the IL28B gene (rs8099917, rs12979860) and virological response of Pakistani hepatitis C virus Genotype 3 patients to pegylated interferon therapy. Int. J. Infect. Dis. 2015, 30, 91-97. [CrossRef] [PubMed]

25. Sarrazin, C.; Susser, S.; Doehring, A.; Lange, C.M.; Müller, T.; Schlecker, C.; Herrmann, E.; Lötsch, J.; Berg, T. Importance of IL28B gene polymorphisms in hepatitis C virus Genotype 2 and 3 infected patients. J. Hepatol. 2011, 54, 415-421. [CrossRef] [PubMed]

26. Khubaib, B.; Idrees, M.; Fatima, Z.; Akram, M.; Afzal, S.; Amin, I.; Shahid, M.; Wasim, M. Evaluation of three techniques for detection of IL28B SNP: A prognostic tool for HCV treatment outcome. J. Dig. Dis. 2017, 18, 404-409. [CrossRef] [PubMed]

27. Ziol, M.; Handra-Luca, A.; Kettaneh, A.; Christidis, C.; Mal, F.; Kazemi, F.; de Lédinghen, V.; Marcellin, P.; Dhumeaux, D.; Trinchet, J.C.; et al. Noninvasive assessment of liver fibrosis by measurement of stiffness in patients with chronic hepatitis C. Hepatology 2005, 41, 48-54. [CrossRef] [PubMed]

28. Zarski, J.P.; Sturm, N.; Guechot, J.; Paris, A.; Zafrani, E.S.; Asselah, T.; Boisson, R.C.; Bosson, J.L.; Guyader, D.; Renversez, J.C.; et al. Comparison of nine blood tests and transient elastography for liver fibrosis in chronic hepatitis C: The ANRS HCEP-23 study. J. Hepatol. 2012, 56, 55-62. [CrossRef] [PubMed]

29. Link, A.; Langner, C.; Schirrmeister, W.; Habendorf, W.; Weigt, J.; Venerito, M.; Tammer, I.; Schlüter, D.; Schlaermann, P.; Meyer, T.F.; et al. Helicobacter pylori vacA genotype is a predominant determinant of immune response to Helicobacter pylori CagA. World J. Gastroenterol. 2017, 23, 4712-4723. [CrossRef] [PubMed]

30. Franck, C.; Hoffmann, A.; Link, A.; Schulz, C.; Wuttig, K.; Becker, E.; Heim, M.; Venerito, M. Prevalence of Helicobacter pylori infection among blood donors in Saxony-Anhalt, Germany-A region at intermediate risk for gastric cancer. Z. Gastroenterol. 2017, 55, 653-656. [CrossRef] [PubMed]

31. Bose, K.; Franck, C.; Müller, M.N.; Canbay, A.; Link, A. Perioperative therapy of oesophagogastric adenocarcinoma: Mainstay and future directions. Gastroenterol. Res. Pract. 2017, 2017, 5651903. [CrossRef] [PubMed]

32. Leja, M.; Axon, A.; Brenner, H. Epidemiology of Helicobacter pylori infection. Helicobacter 2016, $21,3-7$. [CrossRef] [PubMed]

33. Zhang, Y.; Weck, M.N.; Schöttker, B.; Rothenbacher, D.; Brenner, H. Gastric parietal cell antibodies, Helicobacter pylori infection, and chronic atrophic gastritis: Evidence from a large population-based study in Germany. Cancer Epidemiol. Biomark. Prev. 2013, 22, 821-826. [CrossRef] [PubMed] 
34. Hoffmann, A.; Krumbiegel, P.; Richter, T.; Richter, M.; Röder, S.; Rolle-Kampczyk, U.; Herbarth, O. Helicobacter pylori prevalence in children influenced by non-specific antibiotic treatments. Cent. Eur. J. Public Health 2014, 22, 48-53. [PubMed]

35. Roberts, E.A.; Yeung, L. Maternal-Infant Transmission. Hepatology 2002, 36, S106-S113. [PubMed]

36. Mele, A.; Stroffolini, T.; Tosti, M.E.; Corona, R.; Santonastasi, F.; Gallo, G.; Ragni, P.; Balocchini, E.; Bernacchia, R.; Moiraghi, A. Heterosexual transmission of hepatitis C in Italy. J. Med. Virol. 1999, 57, 111-113. [CrossRef]

37. Roberts, S.E.; Morrison-Rees, S.; Samuel, D.G.; Thorne, K.; Akbari, A.; Williams, J.G. Review article: The prevalence of Helicobacter pylori and the incidence of gastric cancer across Europe. Aliment. Pharmacol. Ther. 2016, 43, 334-345. [CrossRef] [PubMed]

38. Mentis, A.; Lehours, P.; Mégraud, F. Epidemiology and diagnosis of Helicobacter pylori infection. Helicobacter 2015, 20, 1-7. [CrossRef] [PubMed]

39. European Monitoring Centre for Drugs and Drug Addiction. European Drug Report 2014: Trends and Developments; European Monitoring Centre for Drugs and Drug Addiction: Lisbon, Portugal, 2014.

40. Stein, M.; Ruggiero, P.; Rappuoli, R.; Bagnoli, F. Helicobacter pylori CagA: From pathogenic mechanisms to its use as an anti-cancer vaccine. Front. Immunol. 2013, 4, 328. [CrossRef] [PubMed]

41. Suerbaum, S.; Achtman, M. Helicobacter pylori: Recombination, population structure and human migrations. Int. J. Med. Microbiol. 2004, 294, 133-139. [CrossRef] [PubMed]

42. Perez-Perez, G.I.; Olivares, A.Z.; Foo, F.Y.; Foo, S.; Neusy, A.J.; Ng, C.; Holzman, R.S.; Marmor, M.; Blaser, M.J. Seroprevalence of Helicobacter pylori in New York City populations originating in East Asia. J. Urban Health 2005, 82, 510-516. [CrossRef] [PubMed]

43. Garcia-Tsao, G.; Abraldes, J.G.; Berzigotti, A.; Bosch, J. Portal hypertensive bleeding in cirrhosis: Risk stratification, diagnosis, and management: 2016 practice guidance by the American Association for the study of liver diseases. Hepatology 2017, 66, 310-335. [CrossRef] [PubMed]

44. González, C.A.; Sala, N.; Capellá, G. Genetic susceptibility and gastric cancer risk. Int. J. Cancer 2002, 100, 249-260. [CrossRef] [PubMed] 